\title{
Self-Efficacy and Performance of Grade 7 Students
}

\author{
Analyn P. Guro \\ Mindanao State University, Marawi City, Philippines
}

\begin{abstract}
Individual person believe his own abilities to meet the challenges in life. In psychology, that belief is called self-efficacy. In general perspective, self-efficacy is the overall belief of individual persons to succeed in every endeavor. This study aimed to determine the grade 7 self-efficacy and its relation to their problem solving performances in math. Qualitative and quantitative approach was used in this survey descriptive survey analysis research. Quantitative data were obtained from students grades in math and scores in the Mathematics Achievement Test of the students. Qualitative data were obtained from student's interview and responses in the Self- Efficacy Questionnaire. Findings revealed that student's self-efficacy wasrated Very Well. This means that they have the capability to do homework, schoolwork, as well as to study their algebra and pass the test. However, achievement test showed that students 'problem solving performances were minimally low in mental math, addition, and subtraction operations and there was significant relationship between the students " self-efficacy and their problem solving performances in math. With these findings, school should regularly hold activities that could enhance and challenge students' mathematical ability and proficiency, and award the winners to boost their ego to keep and do well in their studies.
\end{abstract}

Keywords: self-efficacy, students' performance, mathematics

\section{Introduction}

Many studies in psychology focused on the parenting styles and practices and how these affect the development of children and adolescents. It is interesting to note that parenting styles and practices are closely related. According to Sampaio and Gomide (2006), parenting practices are characterized as strategies and techniques used by parents to guide their child's behavior, whereas parenting style is a result of a set of parenting practices that can, depending on frequency and intensity, shape prosocial or antisocial behavior. The study of parenting style approaches child rearing objectively, investigating the range of parental behaviors that create the emotional milieu in which parent - child interactions are expressed, based on the influence of parents on behavioral, emotional, and intellectual aspects of childhood development.

The development of students self -efficacy is also attributed by the parents parenting styles. Parents have a participatory influence in school matters and hence, they are considered agents for change. Nonetheless, there are some notions that parental involvement in education has been victimized by a change in family structure, e.g. percentages of children in single family homes, number of married mothers of young children and so on. These issues may result that parents may have less time and energy to devote to their children's basic education or to supervise them. It can be argued that family structure and parenting is the greatest cause for the decline in student achievement (Erden and Uredi, 2008). They also play a vital role in the teaching-learning process of their children. However, it is unfortunate that some parents have the -do-what-I-say-not-what-I-do parenting style (children-seechildren-do). They say — don't smoke or — respect women or — cursing is bad, but here they are, saying bad words when they are mad, smoke cigarettes in front of their children. They tell their children to clean their rooms as much as possible, arrange everything, put things in a proper place, but they are not doing it. Parents must be careful with their parenting style, because they influence their children. Whatever children see or hear, children do.

Garganta (2012) said today's youth have learned to create a work of their own, aloof and apathetic to what is happening around them. He added that the stereotyped mindset of Filipino parents that children are not meant to butt in in adult conversation and doing so would mean disrespect to the elderly, is not helping to youth to make 
strong social and political convictions. Dr. Kathy Stansbury said that kids disciplined with positive touch were more likely to comply more often and more quickly with less fussing, (Adewunmi, 2012). The research of Petrill (2012) revealed that working-class and poor parents of any race are more likely to let their children amuse themselves as they see fit once their individual academic tasks, and other works assigned to them.

\section{Methods \\ Research Design}

This study utilized both the qualitative and quantitative methods. Quantitatively, students' grades in Elementary Algebra and students' scores in the Problem Solving Performance Test (PSPT) were used. Qualitatively, students'responses in the Self- efficacy Questionnaire, their answers during the interview, as well as their parents' answers in the Parenting Style Questionnaire were utilized.

\section{Localeof theStudy}

This study was conducted at MSU-Marantao Community High School, Inudaran, Marantao, Lanaodel Surin which there searcher is presently teaching. Marantao, one of the densely populated towns of the Province of LanaodelSur, is said to be the second largest municipalities of the province. It isabout11kilometersonthesouthwing of the City of Marawi.

\section{StatisticalTreatmentof theData}

In the quantitative analysis of data, frequency and percent age distribution were used to tabulate the respondent responses in the questionnaire. Pearson product moment correlation was used to determine the relationship between variables being correlated. Quantitative analysis of data was done through the Statistical Package for Social Sciences (SPSS) for Microsoft Windows.

In the case of qualitative data analysis, descriptive and narrative methods were used capturing the verbatim response of the respondents from interview.

\section{TheRespondentsof theStudy}

The subject participants of the study were theGrade7 students in MSU-Marantao Community High School enrolled in school year 2013-2014 and their parents. Initially, there were 153 Grade 7 students, but since only 115 Self-Efficacy questionnaires were retrieve dafter wards from the students, then only 115parents also were considered and administered with Parenting Style Questionnaire.

\section{TheResearch Instruments}

1. Self-efficacy Questionnaire. This instrument was adopted from Muris, P. (2001). Self-efficacy questionnaire for students is a 24-item scale designed to assess self- efficacy. The questionnaire is divided in to 3 categories; Academic Self-efficacy, Social Self-efficacy, and Emotional Self-efficacy. The scales core for each question ranges from 1to5. Score of 5 is the highest which indicate as the highest level of self-efficacy. Self-efficacy instrument was also validated by the guidance counselor at the DSA Office in MSU, Marawi City.

2. Problem Solving Performance Test (PSPT). This is a self-made test questionnaire. This was given at the end of the second grading period. The test was composed of 34-item word problem solving multiple choices. The coverage of the test questions is based on the lesson of the second grading period. This PSPT will further measure the students' performance in mathematics/algebra and their problem solving ability. The content validation of the PSPT was made through consultation with three experts in math.

\section{Data gathering}

In the data gathering phase, another permit was asked from the School Principal of MSU-Marantao to conduct the study in her school. After securing the permit, the Grade7 math teachers were informed that the PSPT would 
bead ministered to their classes. After the PSPT the students were given the Self-Efficacy questionnaires for them to answer and another questionnaire, Parenting Style, was given them for them to give it to their parents. When the Parenting Style Questionnaires were returned and the data were now tabulated, the students were interviewed about their parents parenting styles. It could have been the parents who were supposed to be interviewed, but they refused giving so many reasons. So, the students took their place. Finally, in the post-data gathering, the data were collated and analyzed to obtain appropriate interpretations.

\section{Analysis of Data}

In the quantitative analysis of data, frequency and percent age distribution were used to tabulate the respondent responses in the questionnaire. Pearson product moment correlation was used to determine the relationship between variables being correlated. Quantitative analysis of data was done through the Statistical Package for Social Sciences (SPSS) for Microsoft Windows. In the case of qualitative data analysis, descriptive and narrative methods were used capturing the verbatim response of the respondents from interview.

\section{Results and Discussion}

This study aimed to determine the Grade 7 students' parents' parenting styles of MSU-Marantao, and how these affect the students' self-efficacy, their problem solving performances, as well as their performances in Elementary Algebra. This study used the qualitative and quantitative research designs. Quantitative data were obtained from the grades of the respondents in one of their subjects, Elementary Algebra, and their scores in the Achievement Test. Qualitative data were obtained from students' responses in the Self-efficacy Questionnaire. The findings of the study were as follows:

The parenting styles of the parents were authoritative, authoritarian, and permissive. Majority of the parentrespondents were authoritative, that is, they had an authoritative parenting style; some, however, were authoritarian and permissive. When parents are authoritative, according to LeFebvre (2004), their children would have high selfesteem, confidence, social competence, respect, responsibility and, hence; have good academic performance. When parents are authoritarian, their children would have low social competence, self-esteem, confidence, and moderate on respect and responsibility, hence, they have average academic performance. When parents are permissive, their children have high self-esteem and social competence; however, they have a lot of problem behavior, hence, they underachieve academically.

The results in the achievement test show that the students' problem solving performances were minimally low in terms of the following operations: mental math (3 correct answers out of 7), addition (4 out of 9), and subtraction ( 2 out of 8 ). They got the right process or solution, but arrived at a wrong answer. In terms of addition-subtraction, multiplication, and division operations, the students' problem solving performances got worse- very low. Majority of them got the wrong since they did not know how to approach the problem. They do not know what operation to use, what process or solution to follow. So, wrong answer. This implies then that students' problem solving performances in mental math, addition, and subtraction need some enhancement and help since they already possess minimum knowledge, skills, and core understanding in Elementary Algebra. More importantly, they need close supervision, if not, individualized instruction on problem solving performances in addition-subtraction, multiplication, and division operations.

Inasmuch as most of the students' parents have an authoritative parenting style, the students' level of academic self-efficacy was very high. In terms of the students' level social self-efficacy, it was, more or less, very high. In terms of their emotional self- efficacy, it was equally very high with academic self-efficacy. In general, the students' level of self-efficacy is very high. This implies that academically, they have the capability to do homework, schoolwork, and pass a test in Elementary Algebra; socially, they are calm, tactful in dealing with other students, classmates, teachers without being angry, rebellious, and unfriendly; emotionally, they could resist classmates' and peer pressure to engage in high risk activities like drug use and alcoholism. 
Basing on their second grading grades in Elementary Algebra, the students' performances in this subject were varied. One of them got a grade of 90-above; another one got 85-89; 9 got 80-84. Most of them (87), however, got 75-79. Finally, 17 of them failed. They, in short, need some follow-up instruction and assistance, not only by their teachers but also by their parents.

In terms of self-efficacy, it was found that there was a significant relationship between the students' academic self-efficacy and the parents' authoritative, authoritarian, and permissive parenting styles. There was a significant relationship only between the students' social self-efficacy and the parents' authoritarian parenting style. There was a significant relationship between the students' emotional self-efficacy vis-à-vis theparents' authoritative and authoritarian parenting styles. There was a significant relationship only between the students' performances in Elementary Algebra and the parents' authoritarian parenting style. There was no significant relationship between the students' performances in Elementary Algebra vis-à-vis authoritative and permissive parenting styles. There was also a significant relationship between the students' problem solving performances in Elementary Algebra vis-à-vis all the three components of self- efficacy: academic, social, and emotional. This means that the students' ${ }^{6}$ selfefficacy, in general, has some bearing and is very important in their Elementary Algebra performance.

\section{Conclusions}

The parents were very supportive in terms of the students' academics and emotions, less supportive on social aspect. The parenting styles of parents, i.e., authoritarian and, more specially, authoritative had some bearing and significant relationship with students' problem solving performances, as well as with their performances in Elementary Algebra. Since most or majority of the student-respondents had an average rating in their high school algebra, their proficiency level based on DepEd's Standard-Based Assessment, K-12 Basic Education Curriculum (2012) is Developing, which implies that the students had a minimum knowledge and skills and core understandings, but they need help throughout their performance. On the one hand, the students' problem solving performances as shown in the results of the Achievement test were minimally low in mental math, addition, and subtraction operations. So, they need some enhancement and help in this area. On the other hand, in terms of addition- subtraction, multiplication, and division operations, the students' problem solving performances were very low. Thus, they need close supervision, if not, individualized instruction on this aspect.

Moreover, the students' levels of self-efficacy were broken down into three: academic, social, and emotional. The students' academic self-efficacy, social self- efficacy, and emotional self-efficacy were almost equally Very High. Hence, having a very high self-efficacy makes the students capable in making homework, schoolwork, and passes a test in Elementary Algebra. They are also capable in dealing with social challenges and in dealing with other students in a calm and tactful way. They have a strong emotional stability to control their personal feelings and to resist classmates' or peer's pressure to engage in high risk activities like drug use and alcoholism.

\section{Implications}

Parents are supportive in terms of students' academics and emotions, less on social aspect. This implies that parents are always supportive when it comes to their child's schooling and personal feelings. This aspect should be taken advantage by children to do better in their academics. Parents should take note that their parenting styles are very significant and are a contributory factor to their child's academic success. Children should also realize that when their parents are authoritative or authoritarian, it does not mean that they are strict, cruel, or unsupportive. Again, it means that they are only after their well-being.

Furthermore, students' self-efficacy has some bearing and is very important in their Elementary Algebra performance. Hence, to maintain a high level of self-efficacy - academically, socially, and emotionally - students should obey their parents, follow their instructions, respect them, and support them all the way. In return, they would be the best parents in the world.

Finally, education is always a corporation among the teachers, the parents, and the students. The teachers should see to it that their students are performing well in class, and prod them when they slack off. Parents should 
always keep track or follow up their child in their schoolwork and school-related activities and offer them support. Children should do their part as students—-study their lessons, respect their teachers, and obey their parents.

\section{Recommendations}

The parents and the students must be the first beneficiaries of the results of this study. The school administrator with the teachers, therefore, should not fail to include the parents in all the students' activities so that the latter's academic performance and status are always kept track. For parents' parenting styles are contributory factor to their child's success in academics, the school must make sure that parents could feel that they are important part of the school--that their presence, cooperation, and support are needed for their child's school life. The school should also do its best to reduce or eliminate class bullies who could affect adversely not only the students 'problem solving performances in particular, but also the academic performance, in general. Students with low and average performances in Elementary Algebra should be afforded with some enhancement or follow-up lessons. Students with poor or very low performances in Elementary Algebra and even in other math subjects should be remediated. That is, they should be given some close supervision or, if possible, some remedial classes. Teachers handling remedial classes should be given service credits to motivate other teachers to do the same. Finally, the school should regularly hold activities that could enhance and challenge students' mathematical ability and proficiency, and award the winners to boost their ego to keep and do well in their studies.

\section{References}

[1] Abesha, A. G. (2012). Effects of parenting styles, academic self - efficacy, and achievement motivation on the academic achievement of university students in Ethiopia.Pert Western Australia.

[2] Amelita H. Baldoque, Juanito D. Yusingco, and Mr. Angel De Leon, Jr. (2007).Today'sMath.Sibs Publishing House, Inc.

[3] Ampuan-Sani, N. B., (2001). Mathematics readiness and the academic performance of sophomore students in elementary algebra: their relationship with some selected variables MSU - External Units. Unpublished dissertation. Mindanao State University - Marawi City.

[4] Bandong, D.G., San Jose, R.M. ( 2010). Real- World Mathematics Elementary Algebra.C\& E Publishing, Inc. 2010.

[5] Belloga, R.S. and Parcon, E.A. (2002).Math Smart 5.Katha Publishing Co., Inc.

[6] Calimlim,, J.O., de Leon, C., Milo, G.A. (1994). Integrated Mathematics.SEDP series.VibalPublishing House, Inc. Copyright 1994. Revised Edition.

[7] Camahalan, F., (2006).Effacts of self-regulated learning on mathematics achievement of selected Southeast Asian children.Journal of instructional psychology.

[8] Cecile M. De Leon (1996).Mathematics Beyond 2000.Vibal Publishing House, Inc.Copyright 1996 1st Edition. $4^{\text {th }}$ Edition.

[9] Cresswell, J. W., (2002). Educational Research: Planning, conducting and evaluating quantitative and qualitative research, OH: Merril PrenticeHall.

[10] Erden, M. and Uredi (2008). The Effect of Perceived Parenting Styles on Self- Regulated learning strategies and motivational Beliefs. International Journal about Parents in Education.

[11] Fast, L. A., Lewis, J., Bryant, M. J., Bocian, K. A., Cardullo, R. A., Rettig, M., Hamond, K. A. (2007).Self - efficacy and standardized test performance. Journal of Educational Psychology.University of California, Riverside.

[12] Heaven, P., and Ciarrochi, J. (2008).Parental styles, gender and the development of hope and self-esteem. European Journal of Personality, 22, 707-724.

[13] Kordi, A. and Baharudin, R. (2010). Parenting attitude and style and its effect on children's school achievements. International Journal of Psychological Studies.Canadian Center of Science Education.

[14] Fraenkel, J. R. \&Wallen, N. E., (2007).How to design and evaluate research in education.Sixth edition.International edition. New York. McGraw-Hill Education (Asia).

[15] Freund, J. E., (2003).Modern Elementary Statistics. Tenth edition. PearsonEducation (ASIA) PTE LTD.

[16] Richards, J. C., et al. (1992). Language teaching and applied statistics.Second edition. Essex: Longman group, UK limited. 